NUGLEAR ACCIDENTS,

DROUGHT, AND FAMINE

108

Lessons Learned in Health Service Delivery to Victims of Slow-Onset Disaster

Jalipa $H$, * Amayun $M^{* * *}$

* World Vision-Mozambique

Maputo, Mozambique

** World Vision Relief and Development-USA

Monrovia, California, USA

Objective: To review some of the lessons learned by World Vision International in its health care programs for famine victims and refugees in Thailand, Ethiopia, Mozambique, and Somalia.

Methods: Experiences in health-service delivery to victims of slow-onset disasters, principally refugee movements and drought/famine in several countries of Asia and Africa, are presented. Lessons learned under the broad categories of planning and design of health programs, staffing and human resource development, logistics; health education, endemic disease control, and health information systems are enumerated and discussed briefly.

Results: Slow-onset disasters, by their very nature, provide health care professionals the space and time to react so that interventions can be initiated to minimize morbidity and mortality. However, there are many factors, such as ethnic rivalry or international politics, that are beyond any single person's or group's control, which greatly impact the effectiveness of health interventions. The significance of cross-cultural factors increasingly have become recognized.

International cooperation is crucial, especially in refugee situations. Health professionals must be prepared to speak to the press and to donors on behalf of their work and the people they serve.

Conclusion: Over the last 10 years, the role of the health professional has changed from simply being a service provider to that of a manager, advocate, and resource mobilizer.
109

\section{The Role of Primary Health Care} in Famine and Refugee Situations

Siegle J, Amayun $M$, *Jalipa $H^{* *}$

* World Vision Relief and Development-USA

Monrovia, California-USA

** World Vision-Mozambique

Maputo, Mozambique

Objective: To examine the appropriateness of a primary health care approach to famine and refugee response program undertaken by World Vision since 1979.

Methods: Records of World Vision's involvement in the Cambodian refugee crisis (1979-1983), Somali refugee crisis (1981-1983), Ethiopia famine(1984-1986), Mozambique drought and civil war (1985-1992), and the current Somalia famine and civil-war (1992-1993) were examined. Health professionals who worked with the organization during the different crises were interviewed.

Results: Primary health care, an approach that has gained worldwide acceptance over the last decade, focuses on services that are culturally appropriate, financially sustainable, and targeted to achieve maximum impact. World Vision's famine and refugee response programs emphasized nutrition (wet feedings and food distribution), training of local volunteers, and control of endemic diseases (principally malaria and diarrhea). Immunization of young children and women of childbearing age was initiated whenever appropriate. Curative care was heavily emphasized during the Cambodian refugee crisis in Thailand, but not in the most recent crises.

Conclusion: Primary health care services, if properly targeted toward women and children, are adequate to reduce morbidity and mortality in refugee and famine situations. It is low cost and has the potential for greater sustainability. The emphasis on training provides service providers a foundation for rehabilitation and development after a crisis ends. 